\title{
Using a DAS28-CRP-steered treat-to-target strategy does not eliminate subclinical inflammation as assessed by ultrasonography in rheumatoid arthritis patients in longstanding clinical remission
}

Lene Terslev ${ }^{1,2^{*}}$ (D), Cecilie Heegaard Brahe ${ }^{1}$, Mikkel Østergaard ${ }^{1,2}$, Viktoria Fana ${ }^{1}$, Mads Ammitzbøll-Danielsen ${ }^{1}$, Torsten Møller', Simon Krabbe ${ }^{1}$, Merete Lund Hetland ${ }^{1,2}$ and Uffe Møller Døhn ${ }^{1}$

\begin{abstract}
Background: Subclinical synovitis by ultrasound is a frequent finding in rheumatoid arthritis (RA) patients in remission and has been shown to be related to erosive progression, risk of flare and unsuccessful drug tapering, but it has not been investigated how a DAS28 T2T-steered strategy in routine care affects the presence of subclinical synovitis in RA patients in remission. The aim of the current study was to investigate the presence of ultrasound-detected subclinical inflammation in RA patients in long-term remission receiving either biological or conventional disease-modifying anti-rheumatic drugs (bDMARD/csDMARD) and, finally, to investigate the presence of ultrasound remission using different ultrasound remission criteria.
\end{abstract}

Methods: Eighty-seven RA patients (42 patients receiving bDMARD and 45 cSDMARD) received DAS28-CRP-steered treatment in routine care and had achieved DAS28-CRP-remission for $\geq 1$ year without radiographic progression. Twenty-four joints were scored 0-3 by ultrasound (elbows, wrists, knees, ankles, metacarpophalangeal and metatarsophalangeal joints 2-5) for grey-scale synovial hypertrophy (GS) and colour Doppler activity (CD) using the OMERACT scoring system. Ultrasound remission was defined as strict (GS score $=0$ and CD score $=0$ ), semi-strict (GS score $\leq 1$ and Doppler score $=0$ ) and Doppler remission (Doppler score $=0$ ).

* Correspondence: lene.terslev.01@regionh.dk

${ }^{1}$ Copenhagen Center for Arthritis Research (COPECARE), Center for Rheumatology and Spine Diseases, Copenhagen University Hospital, Rigshospitalet, Glostrup, Copenhagen, Denmark

2Department of Clinical Medicine, University of Copenhagen, Copenhagen, Denmark

C C The Author(s). 2021 Open Access This article is licensed under a Creative Commons Attribution 4.0 International License, which permits use, sharing, adaptation, distribution and reproduction in any medium or format, as long as you give appropriate credit to the original author(s) and the source, provide a link to the Creative Commons licence, and indicate if changes were made. The images or other third party material in this article are included in the article's Creative Commons licence, unless indicated otherwise in a credit line to the material. If material is not included in the article's Creative Commons licence and your intended use is not permitted by statutory regulation or exceeds the permitted use, you will need to obtain permission directly from the copyright holder. To view a copy of this licence, visit http://creativecommons.org/licenses/by/4.0/. The Creative Commons Public Domain Dedication waiver (http://creativecommons.org/publicdomain/zero/1.0/) applies to the data made available in this article, unless otherwise stated in a credit line to the data. 
(Continued from previous page)

Results: No differences between treatment groups were found for GS sum score and Doppler sum score (median (range) 6 (0-19) and 0 (0-12), respectively). A Doppler score $>0$ in at least 1 joint was seen in 44\%, a GS score $\geq 1$ in at least 1 joint in $93 \%$ and a GS score $\geq 2$ in at least 1 joint in 54\% of patients. Strict ultrasound remission was only observed in bDMARD patients (7\%; $\bar{p}=0.01)$. Thirty-seven per cent were in semi-strict ultrasound remission and $56 \%$ in Doppler remission (no significant difference between groups) with similar results across the subgroups of patients who also fulfilled the ACR-EULAR Boolean-, CDAl- and SDAl-remission criteria.

Conclusions: Ultrasound frequently detected subclinical synovitis in RA patients in longstanding DAS28-remission obtained through a DAS28-CRP-steered strategy. This was independent of treatment and applied ultrasound remission criteria. Strict ultrasound remission was rare.

Keywords: Remission, Ultrasound, Doppler, Treat-to-target, Subclinical synovitis

\section{Background}

The treatment goal in patients with rheumatoid arthritis (RA) is to rapidly suppress inflammation and thereby preventing pain and joint destruction and improving functional ability and quality of life. This was addressed in the EULAR 2010 treat-to-target (T2T) recommendations, where the treatment target was specified as clinical remission or at least low disease activity, assessed by the use of composite measures and when not achieved, adjustment of therapy is recommended [1]. Targeting remission by applying a disease activity score based on a 28 -joint count (DAS28) $<2.6$ as compared to a conventional strategy not using a DAS28-targeted strategy has shown a significant advantage favouring the T2T DAS28 approach [2, 3].

The updated EULAR 2016 T2T recommendations favour ACR-EULAR Boolean-remission over DAS28remission [4], because it is more stringent and better reflects the clinical perception of remission, i.e. the absence of signs and symptoms of significant inflammatory disease activity. DAS28-CRP is still, however, applied in routine care and clinical trials [5]. Despite data showing that subclinical inflammation as detected by ultrasound and magnetic resonance imaging is present in a substantial proportion of patients with RA in clinical remission [6-12], it was decided not to include imaging remission into the updated EULAR T2T recommendations, leaving clinical remission as the therapeutic target [4]. However, data shows that subclinical synovitis detected by ultrasound seems to be independent of the applied clinical remission criteria and type of treatment (conventional synthetic disease-modifying anti-rheumatic drugs (csDMARD) or biological DMARD (bDMARD)) [12-16].

Subclinical synovitis has been shown to be related to erosive progression as well as to the risk of flare and unsuccessful drug tapering, especially when Doppler activity is present $[7,8,17-22]$. Ultrasound remission is therefore generally perceived as an ultrasound disease state without Doppler activity, but different studies put different emphasis on the presence of synovial hypertrophy by grey-scale (GS) ultrasound. Though subclinical synovitis in patients in remission has been assessed previously, none of the studies evaluated patients in longstanding remission obtained through a DAS28 T2T-steered strategy applied in routine care $[6,7,12-16]$.

Therefore, the aims of this study were, in RA patients in longstanding remission obtained by a DAS28CRP T2T-steered strategy in routine care, to investigate if the presence of ultrasound detected subclinical inflammation was less than previously reported; secondly, in this T2T-steered cohort, to assess if bDMARD-treated patients had less subclinical synovitis than csDMARDtreated patients, using both a comprehensive joint assessment and an assessment of the hands only; finally, to investigate the proportion of patients in ultrasound remission when applying three different ultrasound remission criteria.

\section{Material and methods}

The study is a cross-sectional, observational study in patients with RA in sustained DAS28CRP-remission treated with either csDMARD only or bDMARD treatment (as monotherapy or in combination with csDMARD). Patients were recruited from the Center for Rheumatology and Spine Diseases at Rigshospitalet, Glostrup, Denmark. Clinical evaluation and ultrasound examination were conducted on the same day, at the time of inclusion. The local ethics committee found that a formal ethical approval was not needed because of the observational design (H-2-2014FSP53). Despite this, all patients gave written informed consent and the study was conducted in accordance with the Declaration of Helsinki.

The inclusion criteria were RA fulfilling the 2010 EULAR/ACR classification criteria with DAS28-CRP $<2.6$ for at least 1 year documented in at least 3 clinical visits in the DANBIO registry, age $>18$ years, stable treatment with no indication for treatment change for at least 1 year and no glucocorticoid treatment 6 months prior to inclusion and no radiographic progression during the previous year 
assessed with the $\mathrm{x}$-ray of hands and feet by the radiology department.

\section{Clinical evaluation}

The national DANBIO registry is an integrated part of the routine clinical monitoring of RA patients in Denmark [23, 24]. The DANBIO registry is used as a clinical tool in all departments to monitor arthritis patients and their response to treatment or lack thereof and notifies when remission is not reached. For each clinical visit, swollen and tender joint counts of at least the 28 joints included in the DAS28CRP (bilateral wrist, metacarpophalangeal joints (MCPs), proximal interphalangeal joints (PIPs), elbow, shoulder and knee joints) are entered into DANBIO together with visual analogue scale (VAS, $0-100 \mathrm{~mm}$ ) assessments of pain and patient's and physician's global assessment, Health Assessment Questionnaire (HAQ) and C-reactive protein (CRP). From the results of physical examination, patient questionnaires and CRP, the DAS28CRP and the CDAI are automatically calculated at each clinical visit informing the clinician whether DAS28 and/or CDAIremission is obtained. If DAS28CRP $>2.6$, there is an automatic alert to the clinician to change/optimise treatment until DAS28CRP $<2.6$ has been reached. Patients are seen in the out-patient clinic approximately every 3 months to ensure treatment optimisation until remission is obtained. Treatment is escalated according to national $\mathrm{T} 2 \mathrm{~T}$ recommendations in routine care.

\section{Ultrasound}

A GE Logiq ${ }^{\circ}$ E9 R5 (Milwaukee, WI, USA) ultrasound machine with a 5-16ML linear array transducer was used for all examinations. Colour Doppler settings for slow flow [25] were kept unchanged throughout the study. The Doppler frequency was set at $8.2 \mathrm{MHz}$, PRF at 0.4 $\mathrm{kHz}$, wall filter 57 , colour priority at $100 \%$ and Doppler gain just below the noise level. The size and position of the colour box was set to go to the top of the image to recognise artefacts caused by vessels above the joint.

\section{Ultrasound examination}

The ultrasound examinations were performed by experienced ultrasonographers (LT, VF, TM, UMD and MA) with more than 7 years of experience in musculoskeletal ultrasound and scoring of synovitis in clinical and research settings. Prior to the study, reader exercises on scoring joint inflammation were conducted in static images to ensure agreement between observers.

Ultrasound examination techniques were in line with the EULAR scanning guidelines with regard to patient position and scanning planes [26]. In total, 24 joints were evaluated (bilateral elbows, wrists (radio-carpal, inter-carpal and the radioulnar joint-using the highest score of the three), MCP 2-5, knees, talo-crural joints and metatarsophalangeal joints (MTPs) 2-5).

The examination time was approximately $20 \mathrm{~min}$ per patient and representative images of all pathology were stored for each patient. The clinical examination was performed prior to the ultrasound examination by a rheumatologist different to the sonographer who was kept blinded to the results of the clinical examination and laboratory findings.

\section{Image evaluation}

GS and colour Doppler (CD) ultrasound were used to assess synovial hypertrophy and synovial vascularization using the OMERACT definition for synovitis [27] and the EULAR-OMERACT semi-quantitative scoring system (0-3) for grading the two synovitis components (GS and CD) [27, 28]. A score was noted per joint for each modality in order to assess different severities of synovial hypertrophy and $\mathrm{CD}$ activity. In addition, a total grey-scale sum score and a Doppler sum score were calculated for each patient (sum of the scores for all joints with a maximum score of 72). Ultrasound synovial hypertrophy was defined as a GS score $\geq 1$ and synovial hypervascularization as a Doppler score $\geq 1$.

\section{Defining ultrasound remission}

Ultrasound remission status was assessed using three different definitions: strict ultrasound remission (GS score $=0$ and Doppler score $=0$ ), semi-strict ultrasound remission (GS score $\leq 1$ and Doppler score $=0$ ) and Doppler ultrasound remission (Doppler score $=0$, irrespective of the GS score).

\section{Statistics}

Demographic data are presented as median and range. Comparisons between groups were done using MannWhitney's test for continuous data and Pearson chi-square for categorical data with a $p$ value $<0.05$ considered statistically significant. SPSS version 25 was used for statistical analysis.

\section{Results}

Eighty-seven consecutive patients with RA in DAS28CRP-remission for at least 1 year were included; 45 patients received csDMARDs (csDMARD group) while 42 patients received bDMARD either alone or in combination with csDMARDs (bDMARD group). Demographic data for the entire cohort stratified by type of treatment may be seen in Table 1. For all patients, the median DAS28CRP was 1.8 (range 1.1-2.5) and significantly lower in the csDMARD-treated group compared to the bDMARD-treated group. Overall, in the bDMARD group, eight patients (19\%) received bDMARD monotherapy, while the rest received combination therapy with one 
Table 1 Clinical and ultrasound data for the patients in DAS28CRP-remission $\geq 1$ year obtained through a treat-to-target steered strategy

\begin{tabular}{|c|c|c|c|c|}
\hline & $\begin{array}{l}\text { All patients } \\
(n=87)\end{array}$ & $\begin{array}{l}\text { CsDMARD group } \\
(n=45)\end{array}$ & $\begin{array}{l}\text { bDMARD group } \\
(n=42)\end{array}$ & $\begin{array}{l}\text { Difference between } \\
\text { groups ( } p \text { values) }\end{array}$ \\
\hline Age (years) & $61(25-82)$ & $64(31-82)$ & $57(25-82)$ & 0.14 \\
\hline Female gender & $66 \%$ & $62 \%$ & $69 \%$ & 0.50 \\
\hline Disease duration (years) & $10(1-54)$ & $6(1-44)$ & $13(0-2)$ & $<0.001$ \\
\hline Positive rheumatoid factor & $61 \%$ & $56 \%$ & $67 \%$ & 0.29 \\
\hline Positive anti-CCP & $67 \%$ & $56 \%$ & $79 \%$ & 0.02 \\
\hline Erosive disease & $66 \%$ & $51 \%$ & $81 \%$ & 0.003 \\
\hline Number of current DMARDs & $1(0-3)$ & $1(0-3)$ & $1(0-1)$ & 0.003 \\
\hline \multicolumn{5}{|l|}{ Clinical assessment } \\
\hline Swollen joint count (0-28) & $0(0-2)$ & $0(0-2)$ & $0(0-2)$ & 0.71 \\
\hline Tender joint count (0-28) & $0(0-1)$ & $0(0-1)$ & $0(0-1)$ & 0.60 \\
\hline CRP (mg/L) & $5(1-26)$ & $4(1-13)$ & $5(4-26)$ & $<0.001$ \\
\hline DAS28CRP & $1.8(1.1-2.5)$ & $1.7(1.1-2.4)$ & $1.9(1.6-2.5)$ & 0.002 \\
\hline HAQ (0-3) & $0.125(0-1.625)$ & $0(0-0.875)$ & $0.31(0-1.625)$ & 0.002 \\
\hline VAS Global (mm) (0-100) & $13(0-67)$ & $10(0-45)$ & $15(0-67)$ & 0.16 \\
\hline ACR-EULAR* & $1.6(0-7.7)$ & $1.4(0-5.3)$ & $1.8(0-7.7)$ & 0.35 \\
\hline ACR-EULAR-remission* & $77 \%$ & $76 \%$ & $79 \%$ & 0.74 \\
\hline SDAl & $2.1(0.3-8.2)$ & $1.6(0.3-6.1)$ & $2.8(0.5-8.2)$ & 0.05 \\
\hline SDAI-remission & $75 \%$ & $76 \%$ & $74 \%$ & 0.85 \\
\hline \multicolumn{5}{|l|}{ Ultrasound assessment } \\
\hline Grey-scale sum score (0-72) & $6(0-19)$ & $4(1-18)$ & $6.5(0-19)$ & 0.71 \\
\hline Doppler sum score (0-72) & $0(0-12)$ & $0(0-12)$ & $0(0-7)$ & 1.00 \\
\hline Grey-scale sum score (MCP2-5 and wrist) (0-30) & $3(0-18)$ & $3(0-18)$ & $3(0-12)$ & 0.25 \\
\hline Doppler sum score (MCP2-5 and wrist) (0-30) & $0(0-12)$ & $0(0-12)$ & $0(0-5)$ & 0.84 \\
\hline
\end{tabular}

Values are given as median (range) and percentage. Comparison between groups by Mann-Whitney's test and Pearson chi-square with $p<0.05$ considered significant

$D M A R D$ s disease-modifying anti-rheumatic drugs, CRP C-reactive protein, $H A Q$ Health Assessment Questionnaire, VAS visual analogue scale

*Patients in ACR-EULAR Boolean-remission are identical to patients in CDAl-remission

CSDMARD. In the entire cohort, $65(75 \%)$ patients also fulfilled SDAI-remission criteria $(\mathrm{SDAI} \leq 3.3)$, and 67 (77\%) CDAI-remission criteria $(\mathrm{CDAI} \leq 2.8)$. All patients fulfilling the CDAI-remission criteria also fulfilled the ACR-EULAR Boolean-remission criteria and vice versa.

Patients in the bDMARD group as compared to the csDMARD group had significantly longer disease duration; more patients had erosive disease, were anti-CCP positive and had higher CRP, HAQ, DAS28-CRP and SDAI-scores (Table 1). There were no differences in the fraction of patients fulfilling the SDAI-, CDAI- and ACR-EULAR Boolean-remission criteria in the two treatment groups.

Overall, very little clinical residual disease activity was present with 79 of the patients (91\%) having neither clinically swollen nor tender joints in the 28 joints assessed for DAS28-CRP. Five patients (6\%) had a maximum of 2 swollen joints and three patients (3\%) had a maximum of 1 tender joint. None of these patients had both tender and swollen joints.

\section{Ultrasound findings}

For the entire cohort, the GS sum score at patient level was median (range) 6 (0-19) and the Doppler sum score was $0(0-12)$, with no significant differences between treatment groups. When evaluating ultrasound scores only from the hands, the pattern was similar with no significant difference between groups (Table 1).

When assessing 24 joints, $44 \%$ of the patients had Doppler score $>0$ in at least one joint and $93 \%$ of the patients had a GS score $\geq 1$ in at least one joint while 47 patients (54\%) had a GS score $\geq 2$ in at least one joint (no statistically significant difference according to treatment).

When assessing the hands only, $40 \%$ of the patients still had a Doppler score $>0,93 \%$ of the patients had a 
GS score $>1$ while $37 \%$ of the patients had a GS score $>2$ in at least one joint (no statistically significant difference between treatments).

\section{Ultrasound remission}

We only found strict ultrasound remission in $6(7 \%)$ patients in the bDMARD group and in $0(0 \%)$ patients in the csDMARD group $(p=0.01)$ (Table 2). In the entire cohort, 37\% were in semi-strict ultrasound remission and $56 \%$ in Doppler ultrasound remission with no significant difference between treatment groups. Similar results were found for ultrasound remission among the subgroups of patients who, in addition to DAS28-CRPremission, also fulfilled the ACR-EULAR Boolean-remission criteria, CDAI-remission criteria and SDAI-remission criteria (Table 2).

When assessing only the hands, numerically more patients were in semi-strict ultrasound and in Doppler ultrasound remission as compared to the more extensive 24-joint ultrasound assessment but with no difference between treatments (Table 3).

\section{Discussion}

The present study demonstrated subclinical synovitis by ultrasound in the majority of RA patients in longstanding clinical remission that had been obtained through a DAS28CRP T2T-steered strategy in routine care. Furthermore, the patients had very little clinical residual disease activity with only five patients having a maximum of 2 swollen joints. Very few patients were found to be in strict ultrasound remission, and this was only observed in patients treated with bDMARD. Doppler ultrasound remission was obtained by $56 \%$ of patients and was more frequent than the strict and semi-strict ultrasound remission, and independent of treatment type. We had similar findings when assessing only the hands. As DAS28-CRP-remission state does not exclude minimal synovitis, we also assessed the number of patients fulfilling CDAI-, SDAI- and ACR-EULAR Boolean-remission criteria. The proportion of patients fulfilling the different ultrasound remission criteria in these groups were the same as for the DAS28-CRP-remission group.

Our findings of subclinical synovitis regardless of the clinical remission criteria applied and independent of the type of treatment are in line with other studies published over a period of more than 10 years $[12-14,16]$. However, in our study, only $7 \%$ of the patients were in strict ultrasound remission and this was only observed in bDMARD-treated patients. This is overall less than observed in the study by Saleem et al. [13] where strict ultrasound remission was seen in 10\% of the bDMARDtreated patients and in $16 \%$ of the csDMARD-treated patients. Other studies have reported even higher percentages in strict ultrasound remission $(26-35 \%)$ for bDMARD-treated patients in clinical remission [14].

Table 2 Proportion of patients in ultrasound remission, according to different ultrasound remission definitions as well as different clinical remission criteria

\begin{tabular}{|c|c|c|c|c|}
\hline \multicolumn{5}{|l|}{ Patients in DAS28CRP-remission } \\
\hline & $\begin{array}{l}\text { All patients } \\
(n=87)\end{array}$ & $\begin{array}{l}\text { csDMARD group } \\
(n=45)\end{array}$ & $\begin{array}{l}\text { bDMARD group } \\
(n=42)\end{array}$ & $\begin{array}{l}\text { Difference between treatment } \\
\text { groups ( } p \text { value) }\end{array}$ \\
\hline Ultrasound strict remission & $6(7 \%)$ & $0(0 \%)$ & $6(14 \%)$ & 0.01 \\
\hline Ultrasound semi-strict remission & $32(37 \%)$ & $15(33 \%)$ & $17(40 \%)$ & 0.50 \\
\hline Ultrasound Doppler remission & $49(56 \%)$ & $26(58 \%)$ & $23(55 \%)$ & 0.78 \\
\hline \multicolumn{5}{|c|}{ Patients in ACR-EULAR Boolean-remission* } \\
\hline & $\begin{array}{l}\text { All patients } \\
(n=67)\end{array}$ & $\begin{array}{l}\text { csDMARD group } \\
(n=34)\end{array}$ & $\begin{array}{l}\text { bDMARD group } \\
(n=33)\end{array}$ & $\begin{array}{l}\text { Difference between treatment } \\
\text { groups ( } p \text { value) }\end{array}$ \\
\hline Ultrasound strict remission & $6(9 \%)$ & $0(0 \%)$ & $6(18 \%)$ & 0.01 \\
\hline Ultrasound semi-strict remission & $25(37 \%)$ & $12(35 \%)$ & $13(39 \%)$ & 0.73 \\
\hline Ultrasound Doppler remission & $38(57 \%)$ & $21(62 \%)$ & $17(49 \%)$ & 0.40 \\
\hline \multicolumn{5}{|l|}{ Patients in SDAI-remission } \\
\hline & $\begin{array}{l}\text { All patients } \\
(n=65)\end{array}$ & $\begin{array}{l}\text { csDMARD patients } \\
(n=34)\end{array}$ & $\begin{array}{l}\text { bDMARD patients } \\
(n=31)\end{array}$ & $\begin{array}{l}\text { Difference between treatment } \\
\text { groups ( } p \text { value) }\end{array}$ \\
\hline Ultrasound strict remission & $6(9 \%)$ & $0(0 \%)$ & $6(19 \%)$ & 0.007 \\
\hline Ultrasound semi-strict remission & $26(40 \%)$ & $13(38 \%)$ & $13(50 \%)$ & 0.76 \\
\hline Ultrasound Doppler remission & $38(59 \%)$ & $22(58 \%)$ & 16 (51\%) & 0.29 \\
\hline
\end{tabular}

Values are given as number of patients and percentage. Comparison between groups by Pearson chi-square with $p<0.05$ considered significant Ultrasound strict remission no joints with GS score $>0$ and Doppler score $>0$, ultrasound semi-strict remission no joints with GS score $>1$ and Doppler score $>0$, ultrasound Doppler remission no joints with Doppler score $>0$. CSDMARD conventional synthetic disease-modifying anti-rheumatic drug, bDMARD biological disease-modifying anti-rheumatic drug, GS grey scale

*Patients in ACR-EULAR Boolean-remission are identical to patients in CDAl-remission 
Table 3 Proportion of patients in ultrasound remission for the hands only according to different ultrasound remission cut-offs

\begin{tabular}{lllll}
\hline Patients in DAS28CRP-remission & \multicolumn{1}{l}{} \\
\hline & $\begin{array}{l}\text { All patients } \\
(\boldsymbol{n}=\mathbf{8 7})\end{array}$ & $\begin{array}{l}\text { csDMARD patients } \\
(\boldsymbol{n}=\mathbf{4 5})\end{array}$ & $\begin{array}{l}\text { bDMARD patients } \\
(\boldsymbol{n}=\mathbf{4 2})\end{array}$ & $\begin{array}{l}\text { Difference between treatment } \\
\text { groups }(\boldsymbol{p} \text { value })\end{array}$ \\
\hline $\begin{array}{l}\text { Bilateral wrist and MCP2-5 only } \\
\text { Ultrasound strict remission }\end{array}$ & $6(7 \%)$ & $0(0 \%)$ & $6(14 \%)$ & 0.009 \\
Ultrasound semi-strict remission & $43(49 \%)$ & $23(51 \%)$ & $20(48 \%)$ & 0.75 \\
Ultrasound Doppler remission & $52(60 \%)$ & $27(60 \%)$ & $25(60 \%)$ & 0.96
\end{tabular}

Values are given as number of patients and percentage. Comparison between groups by Pearson Chi-Square with $p<0.05$ considered significant Ultrasound strict remission no joints with GS score $>0$ and Doppler score $>0$, ultrasound semi-strict remission no joints with GS score $>1$ and Doppler score $>0$, ultrasound Doppler remission no joints with Doppler score, CSDMARD conventional synthetic disease-modifying anti-rheumatic drug, $b D M A R D$ biological diseasemodifying anti-rheumatic drug, MCP metacarpophalangeal joint, GS grey scale

Such differences between studies most likely relate to differences in the applied scoring systems, hardware and differences in the ultrasonographer's interpretation and scoring of Doppler findings. In the study by Saleem et al. [13], the Doppler activity was scored as none, mild, moderate and severe, and the 'none' and 'mild' scores were grouped as normal, which makes a direct comparison difficult, as any Doppler activity in our study would preclude a patient from being classified as in ultrasound remission.

As the optimal definition for ultrasound remission has yet to be determined, we explored different ultrasound remission criteria in the present study. Most emphasis is often put on the presence of Doppler activity independent of the GS score and we found $56 \%$ of the patients to fulfill the Doppler ultrasound remission criteria. Only $37 \%$ of the patients fulfilled the semi-strict remission criteria in which GS synovial hypertrophy score $=1$ is accepted. The relevance of a GS score $=1$ has been debated, especially in the feet where GS synovial hypertrophy is a frequent finding both in longstanding RA and in healthy controls $[29,30]$. However, a GS score $=1$ for synovial hypertrophy even without Doppler activity has been shown to change during treatment, also in the feet [31, 32]. Furthermore, GS synovial hypertrophy has previously been shown to be related to erosive progression over time [8]. It therefore appears justified to define true ultrasound remission as strict ultrasound remission with a GS score $=0$ and a Doppler score $=0$ despite that this appears difficult to achieve in routine care.

The patients in our study had obtained remission through a DAS28-CRP T2T-steered strategy as applied in routine care; however, the presence of subclinical synovitis appeared the same as in studies where the patients' state of remission was determined by the treating physician and not obtained through a T2T strategy by the use of composite scores [6,13]. DAS28-remission is often related to residual disease activity $[4,33,34]$ whereas the ACR-EULAR Boolean-remission criteria better reflect true clinical remission with only minimal subclinical inflammation also by imaging [35-37]; however, no patients fulfilling the stricter ACR-EULAR Boolean-remission criteria were found to be in strict ultrasound remission in the csDMARD group, and only $7 \%$ of patients in the bDMARD-treated group. We found similar percentages of the patients in CDAI-, SDAI- and ACREULAR Boolean-remission to be in semi-strict ultrasound and in Doppler ultrasound remission as those in DAS28CRP-remission which is in line with a previous study [35].

Though recent studies have shown that ultrasound gives no added value in clinical practise for obtaining clinical remission in early RA patients [38, 39], the current study adds to the large amount of data where, when applying ultrasound for assessing remission, subclinical synovitis is found to be present in patients who has achieved clinical remission, including ACR-EULAR Boolean-remission, in routine care independent of clinical strategy and composite scores applied, number of joints assessed and ultrasound equipment used. Furthermore, data from previous studies have shown that erosive progression is related not only to the presence of Doppler activity in joints of RA patients in remission but also to the presence of GS synovial hypertrophy $[8,40]$ and that the presence of Doppler activity is related to the risk of flare and unsuccessful drug tapering [17-19, 40]. This consequently challenges the use of clinical composite scores alone for determining a state of remission in established RA patients in routine care. The current cross-sectional study cannot address whether patients in remission with subclinical synovitis should be treated differently than patients without subclinical synovitis and studies are needed in this area.

The strengths of our study are that data are representing a routine care setting where a T2T strategy was applied. We have used the OMERACT consensus-based and validated scoring system for scoring synovitis (GS and Doppler) and have assessed multiple joints providing a more comprehensive ultrasound status of the patients. The limitations are that the data are obtained from a single clinical centre and since it is crosssectional, it does not contribute with additional data on 
erosive progression, flare or tapering. Further, the ultrasound-assessed joints are not completely identical to the joints involved in the DAS28. However, we found subclinical inflammation also in the clinically assessed joints.

\section{Conclusion}

Subclinical synovitis detected by ultrasound is present in the vast majority of patients in longstanding DAS28CRP-remission independent of the type of treatment when using a DAS28-CRP T2T-steered strategy in routine care. Remission based on clinical composite scores alone is very rarely equivalent to the complete absence of inflammation by ultrasound and may not be sufficient for establishing a state of remission. Further studies are needed to explore if patients with subclinical inflammation in contrast to patients without would benefit from different treatment strategies.

\section{Acknowledgements}

None

\section{Authors' contributions}

Lene Terslev: drafted the protocol and statistical analysis plan, performed ultrasound examination and clinical examinations and data evaluation and drafted the manuscript. Cecilie Heegaard Brahe: performed clinical examinations and participated in drafting the paper and approved the final version. Mikkel Østergaard: data evaluation, drafting the paper and approved the final version. Viktoria Fana: performed ultrasound examinations and participated in drafting the paper and approved the final version. Mads Ammitzbøll Danielsen: performed ultrasound examinations and participated in drafting the paper and approved the final version. Torsten Møller: performed ultrasound examinations and participated in drafting the paper and approved the final version. Simon Krabbe: performed clinical examinations and participated in drafting the paper and approved the final version. Merete Hetland: participated in drafting the paper and approved the final version. Uffe Møller Døhn: performed ultrasound examination and clinical examinations, data analysis and evaluation and drafted the manuscript. The authors read and approved the final manuscript.

\section{Funding}

No financial support was received.

\section{Availability of data and materials}

The datasets used and/or analysed during the current study are available from the corresponding author on reasonable request.

\section{Ethics approval and consent to participate}

The project was evaluated by the local ethics committee, and it was found that a formal ethical approval was not needed because of the observational design (H-2-2014-FSP53). Despite this, we ensured that all patients gave written informed consent to participate and the study was conducted in accordance with the Declaration of Helsinki.

\section{Consent for publication}

No relevant

\section{Competing interests}

Lene Terslev: speaker fee from AbbVie, Janssen, Roche, Novartis, Pfizer, MSD, BMS and GE

Cecilie Heegaard Brahe: none

Mikkel Østergaard: research support, consultancy fees and/or speaker fees form Abbvie, BMS, Boehringer-Ingelheim, Celgene, Eli Lilly, Hospira, Janssen, Merck, Novartis, Novo, Orion, Pfizer, Regeneron, Roche, Sandoz, Sanofi and UCB

Viktoria Fana: none
Mads Ammitzbøll Danielsen: none

Torsten Møller: none

Simon Krabbe: research support from AbbVie, MSD and Novartis Merete L Hetland: grants from Bristol-Myers Squibb, AbbVie, Roche and Novartis; grants and personal fees from MSD, Biogen and Pfizer; and personal fees from Eli Lilly, Orion Pharma, CellTrion, Samsung Bioepis and Janssen Biologics B.V.

Uffe Møller Døhn: consultancy fees from Eli Lilly, Roche and Novartis; speaker fee from Roche, Novartis

Received: 11 September 2020 Accepted: 19 January 2021

Published online: 01 February 2021

\section{References}

1. Smolen JS, Aletaha D, Bijlsma JW, Breedveld FC, Boumpas D, Burmester G, et al. Treating rheumatoid arthritis to target: recommendations of an international task force. Ann Rheum Dis. 2010;69(4):631-7.

2. Schipper LG, Vermeer M, Kuper HH, Hoekstra MO, Haagsma CJ, Den Broeder $\mathrm{AA}$, et al. A tight control treatment strategy aiming for remission in early rheumatoid arthritis is more effective than usual care treatment in daily clinical practice: a study of two cohorts in the Dutch Rheumatoid Arthritis Monitoring registry. Ann Rheum Dis. 2012;71:845-50.

3. Gullick NJ, Oakley SP, Zain A, Gibson T, Jones T, Mistlin A, et al. Goaldirected therapy for RA in routine practice is associated with improved function in patients with disease duration up to 15 years. Rheumatology (Oxford). 2012;51:759-61.

4. Smolen JS, Breedveld FC, Burmester GR, Bykerk V, Dougados M, Emery $P$, et al. Treating rheumatoid arthritis to target: 2014 update of the recommendations of an international task force. Ann Rheum Dis. 2016; 75:3-15.

5. Gaujoux-Viala C, Mouterde G, Baillet A, Claudepierre P, Fautrel B, Le Loët X, et al. Evaluating disease activity in rheumatoid arthritis: which composite index is best? A systematic literature analysis of studies comparing the psychometric properties of the DAS, DAS28, SDAI and CDAI. Joint Bone Spine. 2012;79(2):149-55.

6. Olmez MO, Gunal EK, Ureyen SB, Keskin H, Ozturk AB, Yeter G, et al. Comparison of composite indices with global synovitis score on ultrasound for detecting remission. Clin Rheumatol. 2018;37:1111-4.

7. Brown AK, Quinn MA, Karim Z, Conaghan PG, Peterfy CG, Hensor E, et al. Presence of significant synovitis in rheumatoid arthritis patients with disease-modifying antirheumatic drug-induced clinical remission: evidence from an imaging study may explain structural progression. Arthritis Rheum. 2006;54(12):3761-73.

8. Brown AK, Conaghan PG, Karim Z, Quinn MA, Ikeda K, Peterfy CG, et al. An explanation for the apparent dissociation between clinical remission and continued structural deterioration in rheumatoid arthritis. Arthritis Rheum. 2008;58(10):2958-67.

9. Wakefield RJ, Freeston JE, Hensor EM, Bryer D, Quinn MA, Emery P. Delay in imaging versus clinical response: a rationale for prolonged treatment with anti-tumor necrosis factor medication in early rheumatoid arthritis. Arthritis Rheum. 2007:57(8):1564-7.

10. Zhang $\mathrm{H}, \mathrm{Xu} \mathrm{H}$, Chen $\mathrm{S}$, Mao X. The application value of MRI in the diagnosis of subclinical inflammation in patients with rheumatoid arthritis in remission. J Orthop Surg Res. 2018;13(1):164

11. Gandjbakhch F, Haavardsholm EA, Conaghan PG, Ejbjerg B, Foltz V, Brown $A K$, et al. Determining a magnetic resonance imaging inflammatory activity acceptable state without subsequent radiographic progression in rheumatoid arthritis: results from a followup MRI study of 254 patients in clinical remission or low disease activity. J Rheumatol. 2014:41(2):398-406.

12. Zufferey $P$, Möller B, Brulhart L, Tamborrini G, Scherer A, Finckh A, Ziswiler HR. Persistence of ultrasound synovitis in patients with rheumatoid arthritis fulfilling the DAS28 and/or the new ACR/EULAR RA remission definitions: results of an observational cohort study. Joint Bone Spine. 2014;81(5):426-32.

13. Saleem B, Brown AK, Keen H, Nizam S, Freeston J, Karim Z, et al. Disease remission state in patients treated with the combination of tumor necrosis factor blockade and methotrexate or with disease-modifying antirheumatic drugs: a clinical and imaging comparative study. Arthritis Rheum. 2009;60(7): 1915-22.

14. Spinella A, Sandri G, Carpenito G, Belletti L, Mascia MT. The discrepancy between clinical and ultrasonographic remission in rheumatoid arthritis is 
not related to therapy or autoantibody status. Rheumatol Int. 2012;32(12): 3917-21.

15. Geng Y, Han J, Deng X, Zhang Z. Presence of power Doppler synovitis in rheumatoid arthritis patients with synthetic and/or biological diseasemodifying anti-rheumatic drug-induced clinical remission: experience from a Chinese cohort. Clin Rheumatol. 2014;33(8):1061-6.

16. Cruces M, Al Snih S, Serra-Bonett N, Rivas JC. Subclinical synovitis measured by ultrasound in rheumatoid arthritis patients with clinical remission induced by synthetic and biological modifying disease drugs. Reumatol Clin. 2019;15(4):218-22.

17. Scirè CA, Montecucco C, Codullo V, Epis O, Todoerti M, Caporali R. Ultrasonographic evaluation of joint involvement in early rheumatoid arthritis in clinical remission: power Doppler signal predicts short-term relapse. Rheumatology (Oxford). 2009;48(9):1092-7.

18. Saleem B, Brown AK, Quinn M, Karim Z, Hensor EM, Conaghan P, et al. Can flare be predicted in DMARD treated RA patients in remission, and is it important? A cohort study. Ann Rheum Dis. 2012;11(8):1316-21.

19. Foltz V, Gandjbakhch F, Etchepare F, Rosenberg C, Tanguy ML, Rozenberg S, et al. Power Doppler ultrasound, but not low-field magnetic resonance imaging, predicts relapse and radiographic disease progression in rheumatoid arthritis patients with low levels of disease activity. Arthritis Rheum. 2012;64(1):67-76.

20. Nguyen H, Ruyssen-Witrand A, Gandjbakhch F, Constantin A, Foltz V, Cantagrel A. Prevalence of ultrasound-detected residual synovitis and risk of relapse and structural progression in rheumatoid arthritis patients in clinical remission: a systematic review and meta-analysis. Rheumatology (Oxford). 2014;53(11):2110-8.

21. Naredo E, Valor L, De la Torre I, Montoro M, Bello N, Martínez-Barrio J, et al. Predictive value of Doppler ultrasound-detected synovitis in relation to failed tapering of biologic therapy in patients with rheumatoid arthritis. Rheumatology (Oxford). 2015;54(8):1408-14.

22. Alivernini S, Peluso G, Fedele AL, Tolusso B, Gremese E, Ferraccioli G. Tapering and discontinuation of TNF-a blockers without disease relapse using ultrasonography as a tool to identify patients with rheumatoid arthritis in clinical and histological remission. Arthritis Res Ther. 2016;18:39.

23. Ibfelt EH, Jensen DV, Hetland ML. The Danish nationwide clinical register for patients with rheumatoid arthritis: DANBIO. Clin Epidemiol. 2016;8:737-42.

24. Ibfelt EH, Sørensen J, Jensen DV, Dreyer L, Schiøttz-Christensen B, Thygesen $\mathrm{PH}$, et al. Validity and completeness of rheumatoid arthritis diagnoses in the nationwide DANBIO clinical register and the Danish National Patient Registry. Clin Epidemiol. 2017;9:627-32.

25. Torp-Pedersen S, Terslev L. Settings and artefacts relevant in colour/power Doppler ultrasound in rheumatology. Ann Rheum Dis. 2008;67(2):143-9.

26. Möller I, Janta I, Backhaus M, Ohrndorf S, Bong DA, Martinoli C, et al. The 2017 EULAR standardised procedures for ultrasound imaging in rheumatology. Ann Rheum Dis. 2017;76(12):1974-9.

27. D'Agostino MA, Terslev L, Aegerter P, Backhaus M, Balint P, Bruyn GA, et al. Scoring ultrasound synovitis in rheumatoid arthritis: a EULAR-OMERACT ultrasound taskforce - part 1: definition and development of a standardized, consensus-based scoring system. RMD Open. 2017;3:e000428.

28. Terslev L, Naredo E, Aegerter P, Wakefield RJ, Backhaus M, Balint P, et al. Scoring ultrasound synovitis in rheumatoid arthritis: a EULAR-OMERACT ultrasound taskforce-part 2: reliability and application to multiple joints of a standardised consensus-based scoring system. RMD Open. 2017;3(1):e000427.

29. Witt M, Mueller F, Nigg A, Reindl C, Leipe J, Proft F, et al. Relevance of grade gray-scale ultrasound findings in wrists and small joints to the assessment of subclinical synovitis in rheumatoid arthritis. Arthritis Rheum. 2013;65(7):1694-701.

30. Padovano I, Costantino F, Breban M, D'Agostino MA. Prevalence of ultrasound synovial inflammatory findings in healthy subjects. Ann Rheum Dis. 2016;75(10):1819-23.

31. Terslev L, Østergaard M, Sexton J, Hammer HB. Synovial hypertrophy without Doppler in the feet changes during treatment: results from a longitudinal study of rheumatoid arthritis patients initiating biological treatment. Rheumatology. 2020;59(7):1765-67. https://doi.org/10.1093/ rheumatology/kez607.

32. Terslev L, Østergaard M, Sexton J, Hammer HB. Is synovial hypertrophy without Doppler activity sensitive to change? Post-hoc analysis from a rheumatoid arthritis ultrasound study. Arthritis Res Ther. 2018;20(1):224

33. Mäkinen $H$, Kautiainen $H$, Hannonen P, Sokka T. Is DAS28 an appropriate tool to assess remission in rheumatoid arthritis? Ann Rheum Dis. 2005; 64(10):1410-3.
34. Fleischmann R, van der Heijde D, Koenig AS, Pedersen R, Szumski A, Marshall L, et al. How much does Disease Activity Score in 28 joints ESR and CRP calculations underestimate disease activity compared with the Simplified Disease Activity Index? Ann Rheum Dis. 2015;74:1132-7.

35. Sakellariou G, Scire CA, Verstappen SM, Montecucco C, Caporali R. In patients with early rheumatoid arthritis, the new ACR/EULAR definition of remission identifies patients with persistent absence of functional disability and suppression of ultrasonographic synovitis. Ann Rheum Dis. 2013;72:245-9.

36. Aletaha D, Smolen JS. Remission in rheumatoid arthritis: missing objectives by using inadequate DAS28 targets. Nat Rev Rheumatol. 2019;15(11):633-4.

37. Saleem B, Brown AK, Keen H, Nizam S, Freeston J, Wakefield R, et al. Should imaging be a component of rheumatoid arthritis remission criteria? A comparison between traditional and modified composite remission scores and imaging assessments. Ann Rheum Dis. 2011:70(5):792-8.

38. Dale J, Stirling A, Zhang R, Purves D, Foley J, Sambrook M, et al. Targeting ultrasound remission in early rheumatoid arthritis: the results of the TaSER study, a randomised clinical trial. Ann Rheum Dis. 2016;75:1043-50.

39. Haavardsholm EA, Aga AB, Olsen IC, Lillegraven S, Hammer HB, Uhlig T, et al. Ultrasound in management of rheumatoid arthritis: ARCTIC randomised controlled strategy trial. BMJ. 2016;16:354-4205.

40. Han J, Geng Y, Deng X, Zhang Z. Subclinical synovitis assessed by ultrasound predicts flare and progressive bone erosion in rheumatoid arthritis patients with clinical remission: a systematic review and metaanalysis. J Rheumatol. 2016;43(11):2010-8.

\section{Publisher's Note}

Springer Nature remains neutral with regard to jurisdictional claims in published maps and institutional affiliations.
Ready to submit your research? Choose BMC and benefit from:

- fast, convenient online submission

- thorough peer review by experienced researchers in your field

- rapid publication on acceptance

- support for research data, including large and complex data types

- gold Open Access which fosters wider collaboration and increased citations

- maximum visibility for your research: over $100 \mathrm{M}$ website views per year

At $\mathrm{BMC}$, research is always in progress.

Learn more biomedcentral.com/submissions 